\title{
Numerical Investigation of Laminar Natural Convection in Inclined Square Enclosure with the Influence of Discrete Heat Source
}

\author{
Chithra Devaraj, ${ }^{1}$ Eswaramurthi Muthuswamy, ${ }^{2}$ and Sundararaj Kandasamy ${ }^{1}$ \\ ${ }^{1}$ Sri Ramakrishna Engineering College, Vattamalaipalayam, NGGO Colony, Coimbatore 641 022, India \\ ${ }^{2}$ Velalar College of Engineering and Technology, Thindal, Erode, Tamil Nadu 638 012, India \\ Correspondence should be addressed to Chithra Devaraj; devarajchithra@yahoo.co.in
}

Received 14 May 2015; Accepted 21 July 2015

Academic Editor: Qiuwang Wang

Copyright (C) 2015 Chithra Devaraj et al. This is an open access article distributed under the Creative Commons Attribution License, which permits unrestricted use, distribution, and reproduction in any medium, provided the original work is properly cited.

\begin{abstract}
Natural convection heat transfer in a two-dimensional square enclosure at various angles of inclination is investigated numerically using a finite volume based computational procedure. The heat transfer is from a constant temperature heat source of finite length centred at one of the walls to the cold wall on the opposite side while the remaining walls are insulated. The effect of area ratio of the heat source $A$ from 0.2 to 1.0 , Rayleigh number Ra from $10^{3}$ to $10^{7}$, and angle of inclination of the enclosure $\theta$ varying from $0^{\circ}$ to $360^{\circ}$ on the flow field and heat transfer characteristics are investigated. Streamline and isothermal line patterns are found to be similar at low Rayleigh numbers whereas at high Rayleigh numbers the differences are significant due to the influence of the parameters considered. Average Nusselt number decreases drastically as the position of the heat source is moved above the horizontal centre line of the enclosure. Correlation of the average Nusselt number which depends on the parameters of interest is obtained in the general form $C \mathrm{Ra}^{m} A^{n}$. The correlation coefficients are determined by multiple regression analysis for the entire range of Rayleigh numbers analysed and the values found by correlation equations are in good agreement with the numerical results.
\end{abstract}

\section{Introduction}

Natural convection heat transfer in enclosures has been extensively studied by researchers, because of its practical significance in science and technology. Applications include heating and cooling of building spaces, solar energy collectors, heat exchangers, and effective cooling of electronic components and machinery. The fluid flow and heat transfer behaviour of such systems are analysed numerically and experimentally by a number of researchers, incorporating different geometrical and thermal boundary conditions, from low to high Rayleigh numbers. The studies conducted by different groups were extensively summarized by Wan et al. [1] and a set of benchmark quality data was also presented in this study for the natural convection range of $10^{3} \leq \mathrm{Ra} \leq 10^{8}$. On the other hand, several investigations [2-4] were carried out by the researchers on high Rayleigh numbers above $10^{8}$ where flow becomes turbulent for which numerical solutions are obtained by applying suitable turbulence models. Mao and Zhang [5] have carried out numerical simulation of turbulent natural convection of compressible air in tall cavities to evaluate the accuracy of turbulent models for various temperature boundary conditions. This study reveals that $k-\epsilon$ turbulence model is good in predicting velocity distribution while LES model is good in predicting temperature distribution at high Rayleigh numbers. Unsteady natural convection in a rectangular cavity, numerically investigated by Patterson and Imberger [6], shows that the transient flows strongly depend on the Prandtl number Pr and ultimately converge to identical steady state solutions. The numerical analysis conducted on convection in a cavity with variable viscosity fluid by Kandaswamy et al. [7] confirms that the heat transfer rate increases with the increase in viscosity of the fluid. Analytical studies $[8,9]$ on natural convection in a cavity with volumetric heat generation exemplify the convergence behaviour of various computational methods. A finite method approach by Saha et al. [10] for natural convection in a square tilt open cavity reveals the strong influence of the inclination angle of the cavity on convection heat transfer in addition to the influence of thermal boundary 
conditions. Corcione [11] has applied SIMPLER algorithm to determine the effect of thermal boundary conditions at the sidewalls on natural convection in a rectangular enclosure heated from below and cooled from above for the range of Rayleigh numbers between $10^{3}$ and $10^{6}$. A study on laminar natural convection in shallow air filled rectangular cavities was presented by Samy and Elsherbiny [12] which showed strong dependency of natural convection heat transfer on Rayleigh number, enclosure aspect ratio, and angle of inclination of the enclosure. Aminossadati and Ghasemi [13] investigated the effects of orientation of an inclined enclosure with two adjacent sidewalls at different temperatures on natural convection heat transfer and observed that at high Rayleigh numbers the flow pattern and the rate of heat transfer depend on the angle of inclination of the enclosure. Kandaswamy and Eswaramurthi $[14,15]$ have focused their study on the determination of the effect of density maximum of water around $4^{\circ} \mathrm{C}$ on natural convection in a square porous enclosure applying finite volume method. The influences of porosity, Grashof number, Darcy number, and internal heat generation on natural convection heat transfer were presented in detail in these studies.

Numerical and experimental studies were conducted by different researchers by introducing geometrical features such as baffles, partition walls, fins, and conducting blocks proposing various heat transfer applications [16-19]. In each study, the configuration is described to affect the flow pattern within the enclosure which in turn influences the natural convection heat transfer. A number of studies on square enclosures with time dependent boundary conditions were found in the literature. For illustration, Aswatha et al. [20] applied finite volume method to study the effect of different thermal boundary conditions at bottom wall such as uniform/sinusoidal/linearly varying temperatures on natural convection in enclosures. The results presented from the abovementioned study show that uniform temperature gives higher Nusselt number compared to the sinusoidal and linearly varying bottom wall temperature cases.

In many practical situations, there is a need to view the natural convection in inclined enclosures where the heating component which can be treated as heat source does not spread over the entire length of the inner wall. The directions of gravitational and buoyancy forces remain the same, irrespective of the changes in the angle of inclination of the enclosure which alters the position of the heat source. The combined effect of size of the heat source and the angle of inclination causes additional changes in the flow pattern and the heat transfer characteristics. In the present study, natural convection phenomena in the enclosure for steady laminar flow are investigated for different values of area ratios of the heat source in the range of 0.2 to 1.0 and the angle of inclination varied from $0^{\circ}$ to $360^{\circ}$. Each configuration is analysed for various laminar ranges of Rayleigh numbers, $10^{3} \leq \mathrm{Ra} \leq 10^{7}$.

\section{Mathematical Formulation}

The schematic diagram of the two dimensional square enclosure of size $L \times L$, consisting of a discrete heat source of length

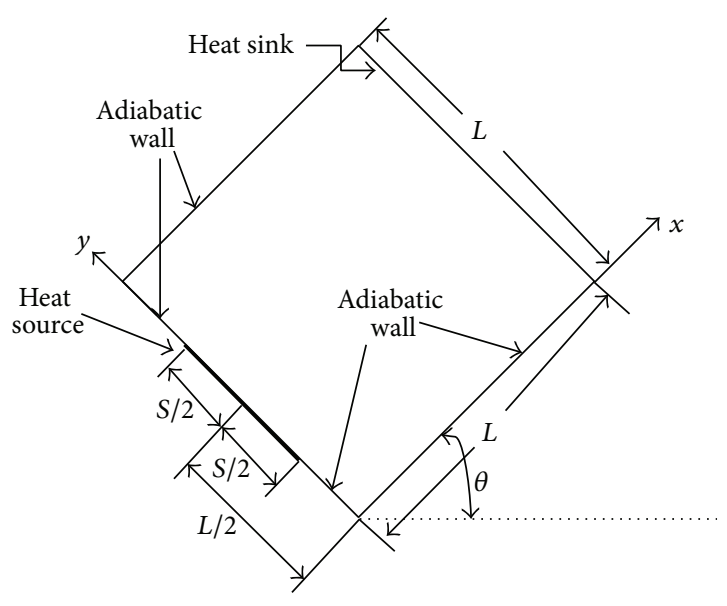

FIGURE 1: Schematic of the square enclosure with segmental heat source.

$S$ at a constant temperature $T_{h}$ at one of its inner walls, is depicted in Figure 1. The wall opposite to the heat source acts as heat sink at constant temperature $T_{c}$. Except the heat source and the sink, the remaining parts of the enclosure walls are assumed to be adiabatic. The origin of the coordinate system is fixed at one corner of the wall containing heat source. Numerical analyses are carried out for different area ratio of heat source $S / L$ equal to $0.2,0.4,0.6,0.8$, and 1.0 assuming that the enclosure contains fluid which is incompressible and laminar. Except the density which is approximated by the Boussinesq model, the fluid properties are assumed to be constant as elaborated by Gray and Giorgini [21]. Heat is transferred from the heat source to the cold wall. Thermally induced density gradient develops a buoyant flow and the gravitational force always acts on the fluid particles in the vertically downward direction irrespective of the angle of inclination of the enclosure.

2.1. Governing Equations. Conservation of mass, momentum, and energy equations are the governing equations to be solved for natural convection flow:

$$
\begin{aligned}
& \text { Continuity: } \frac{\partial u}{\partial x}+\frac{\partial v}{\partial y}=0 \\
& x \text {-Momentum: } u \frac{\partial u}{\partial x}+v \frac{\partial u}{\partial y} \\
& =-\frac{1}{\rho} \frac{\partial p}{\partial x}+\nu\left(\frac{\partial^{2} u}{\partial x^{2}}+\frac{\partial^{2} u}{\partial y^{2}}\right)+g \beta\left(T_{h}-T_{c}\right) \sin \theta \\
& y \text {-Momentum: } u \frac{\partial v}{\partial x}+v \frac{\partial v}{\partial y} \\
& =-\frac{1}{\rho} \frac{\partial p}{\partial y}+\nu\left(\frac{\partial^{2} v}{\partial x^{2}}+\frac{\partial^{2} v}{\partial y^{2}}\right)+g \beta\left(T_{h}-T_{c}\right) \cos \theta \\
& \text { Energy: } u \frac{\partial T}{\partial x}+v \frac{\partial T}{\partial y}=\alpha\left(\frac{\partial^{2} T}{\partial x^{2}}+\frac{\partial^{2} T}{\partial y^{2}}\right) \text {. }
\end{aligned}
$$




\subsection{Boundary Conditions}

Bottom wall: $(0 \leq x \leq L ; y=0):(\partial T / \partial y)(x, 0)=0$.

Top wall: $(0 \leq x \leq L ; y=L):(\partial T / \partial y)(x, L)=0$.

Heat source $(x=0 ;[L / 2-S / 2] \leq y \leq[L / 2+S / 2])$ : $T(0, y)=T_{h}$.

Left wall lower side to heat source: $(x=0 ; 0 \leq y \leq$ $[L / 2-S / 2]):(\partial T / \partial x)(0, y)=0$.

Left wall upper side to heat source: $(x=0$; $[L / 2+$ $S / 2] \leq y \leq L):(\partial T / \partial x)(0, y)=0$.

Right wall: $(x=L ; 0 \leq y \leq L): T(L, y)=T_{c}$.

The properties of the fluid and the acceleration due to gravity are assigned with the appropriate values to obtain the desired Rayleigh number which is given by

$$
\mathrm{Ra}=\frac{g \beta L^{3}\left(T_{h}-T_{c}\right)}{\nu \alpha} .
$$

The average Nusselt number over the cold wall, which is a measure of convection heat transfer in the enclosure, is estimated by using the relation

$$
\mathrm{Nu}_{\mathrm{avg}}=\frac{-1}{L} \int_{0}^{L}\left(\frac{\partial T}{\partial x}\right) d y .
$$

\section{Computational Method and Grid Independence Study}

In the present study, the finite volume based computational procedure is applied to solve the governing equations. The SIMPLE algorithm suggested by Patankar [22] is used for pressure velocity coupling and the second order upwind scheme is used for solving momentum and energy equations. Velocity gradients of the fluid would be high near the inner wall due to the boundary layer formation in comparison with the far field region. Rectangular form grid structure is created as illustrated in Figure 2 with fine grids close to the inner wall to capture the boundary layer accurately and with coarse grids near the centre of the enclosure to reduce the computational time. Grid independent test is conducted for grid sizes $15 \times 15,20 \times 20,30 \times 30,40 \times 40,50 \times 50,60 \times 60$, and $70 \times 70$ for a typical square enclosure with heat source forming over the complete left wall $(S=L)$, top and bottom adiabatic walls, and complete right wall (cold surface) acting as heat sink. The variations of local Nusselt number over the cold wall for different grid structures at Rayleigh numbers $10^{4}$ and $10^{6}$ are shown in Figure 3. Grid comparison indicates that grid independent results are obtained for grid sizes $40 \times 40$ and above. In order to ensure better accuracy of results, grid structure $60 \times 60$ is selected as the ideal one for all the analyses in the present study. The convergence criteria were set to $10^{-6}$ for all the relative (scaled) residuals.

\section{Validation Study}

The methodology applied in the present study is validated rigorously by conducting similar studies reported by Wan

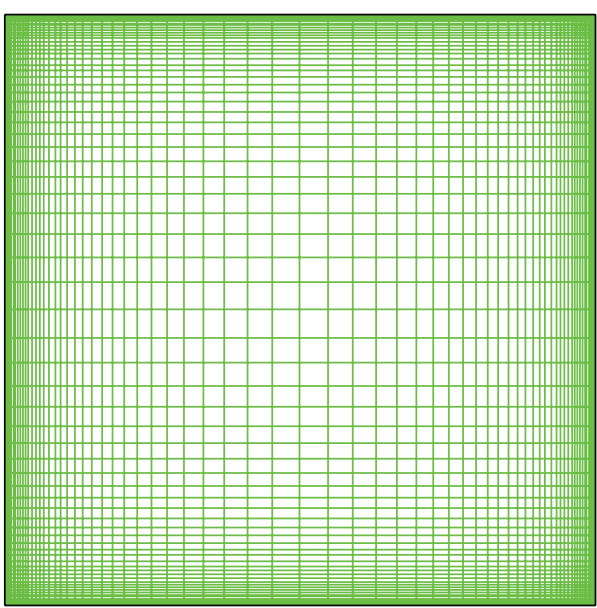

FiguRE 2: Grid structure.

et al. [1] as benchmark data for a wide range of Rayleigh numbers. Contour plots and $X Y$-plots of various parameters are compared and found to produce similar results between the two studies. The comparison of nondimensional horizontal velocities $(u)$ at the midwidth $(x=0.5)$ is presented in Figure 4 to demonstrate the attainment of validation study. Pointwise measurements for the Rayleigh numbers $10^{3}$ to $10^{6}$ are perceived to be in good agreement between the two results. The lack of comparison in the pointwise measurement begins to appear for Rayleigh number equal to $10^{7}$ at few corresponding points of the cavity. For example there is a maximum difference of $10 \%$ for Rayleigh number $10^{7}$ at 0.1 unit distances from the top and bottom walls of the cavity due to high velocity gradients at these levels. However, the present study is focused on the laminar range of Rayleigh numbers not exceeding $10^{7}$.

\section{Results and Discussion}

The results of numerical investigation focused on the influence of area ratio of the heat source and the angle of inclination of the enclosure for Rayleigh numbers $10^{3}$ to $10^{7}$ are presented in this section. Contour plots are used for qualitative description considering typical cavities with heat source area ratios 0.4 and 0.8 and angles of inclination $0^{\circ}$ and $60^{\circ}$. The influences on performance parameters are described quantitatively using $X Y$-plots.

5.1. Influence of Area Ratio and Angle of Inclination on Flow Pattern. Figure 5 shows the results associated with flow field in terms of streamlines for enclosure angles $0^{\circ}$ and $60^{\circ}$ with area ratios equal to 0.4 and 0.8 , respectively, for different Rayleigh numbers. At low Rayleigh numbers the viscous forces are more predominant over buoyant forces due to which the flow circulations are weak. The influences of enclosure angle of inclination and the area ratio on streamline pattern are less significant at low Rayleigh numbers up to $10^{4}$ and the streamlines obtained are concentric forming single cell flow pattern. The development of the single cell is in 

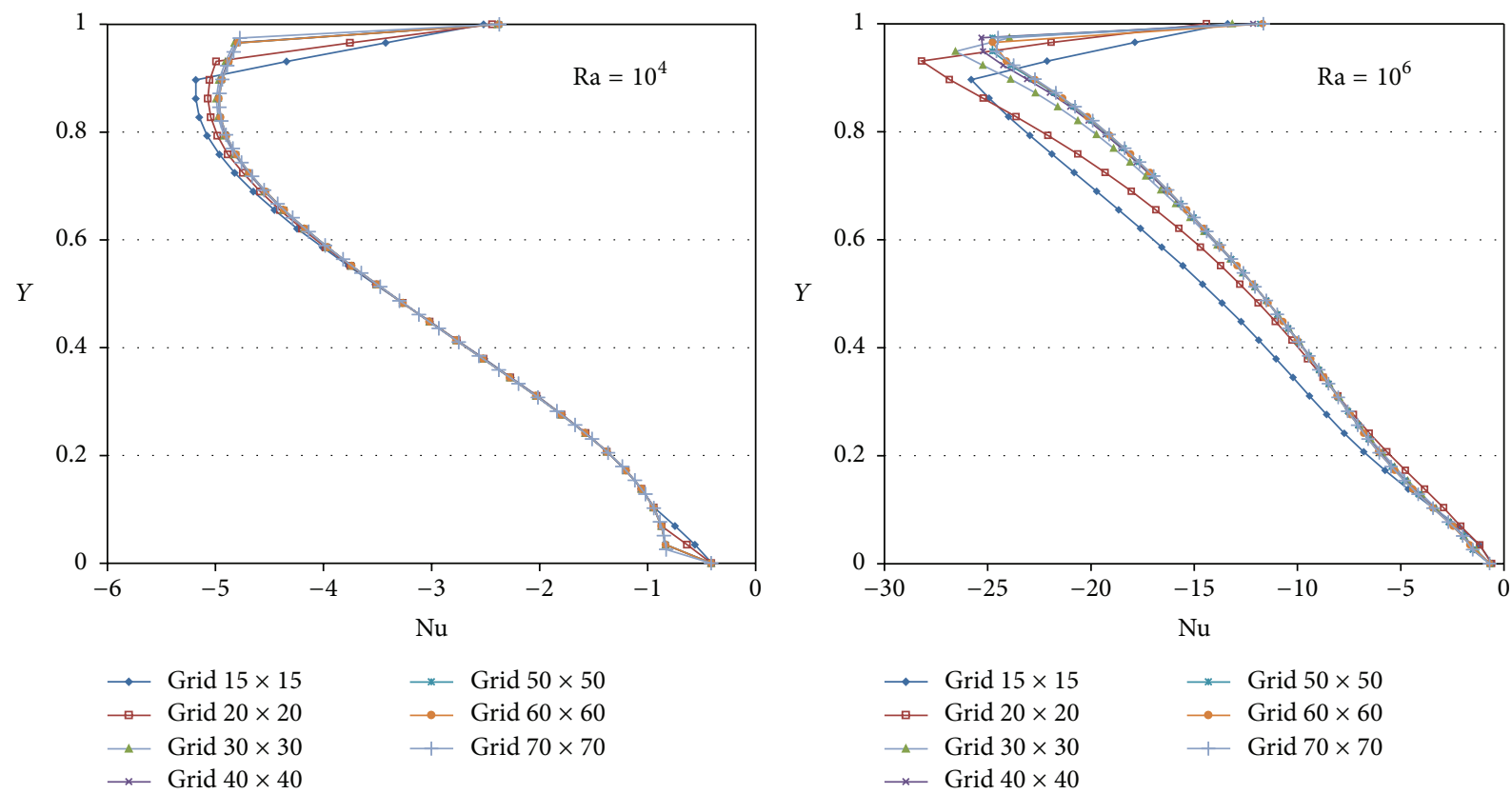

FIGURE 3: Comparison of grid structures.
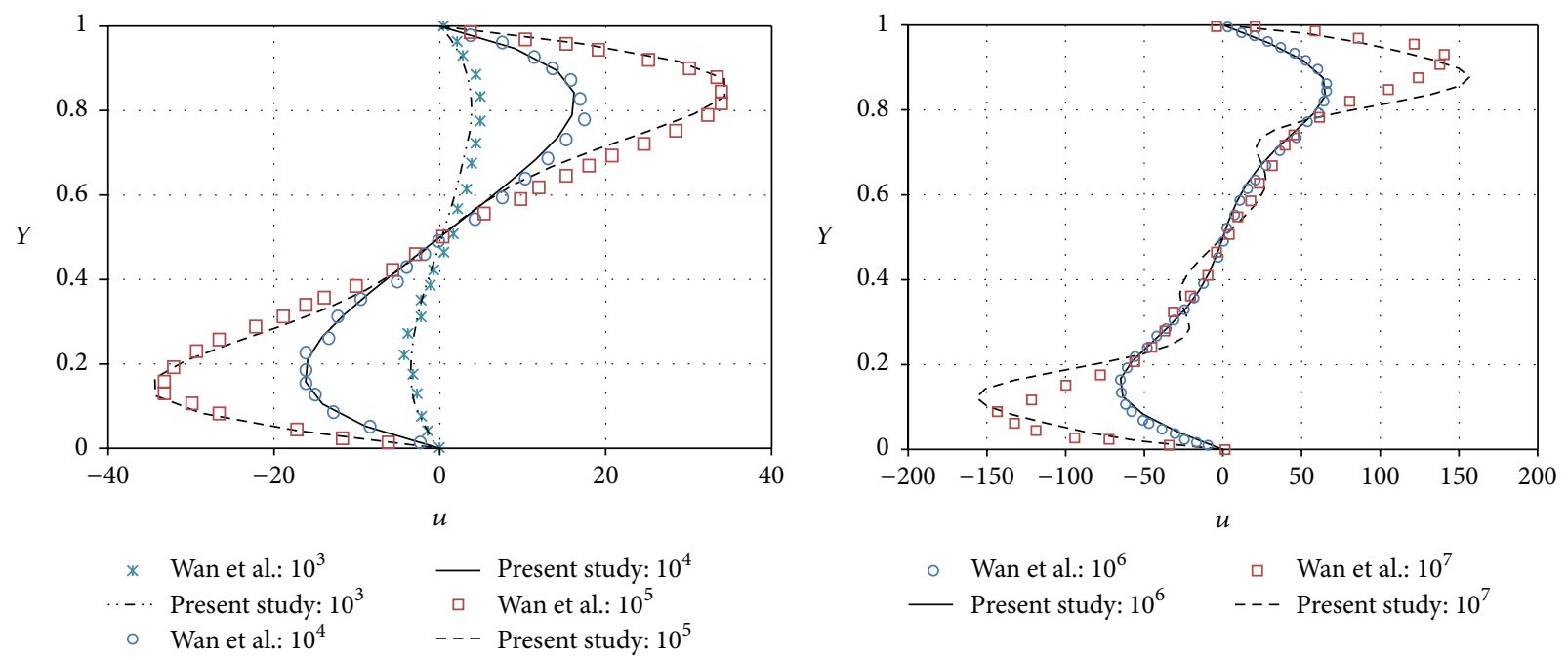

FIGURE 4: Comparison of horizontal velocities $(u)$ at the midwidth $(x=0.5)$.

the clockwise direction due to the rise of the fluid near the hot wall and consequent falling of the fluid near the cold wall. As Rayleigh number increases, the higher buoyant forces alter the flow pattern and the streamlines are closely spaced near the walls. It is an indication of faster moving fluid particles intensifying natural convection heat transfer. Formation of the streamline at high Rayleigh numbers is found to additionally depend on the area ratio of the heat source and the angle of inclination of the enclosure. For instance, for $0^{\circ}$ angle of inclination of the enclosure the flow field tends to evolve into two counter-rotating cells at Rayleigh number equal to $10^{5}$ where such evolution was initiated only at Rayleigh number equal to $10^{6}$ for $60^{\circ}$ angle of inclination of the enclosure. As the Rayleigh number increases, the streamline spacing decreases and hence the magnitude of fluid velocity increases. When the enclosure is not inclined, the pattern of the streamline spacing is not symmetrical on the upper and lower sides of the heat source. More closely packed streamlines are noticed on the upper side of the hot surface. For $60^{\circ}$ angle of inclination of enclosure the streamline spacing pattern appears symmetrically on the upper and lower sides of the hot surface.

Isothermal patterns for the area ratios 0.4 and 0.8 and the angles of inclination $0^{\circ}$ and $60^{\circ}$ in Figure 6 show the influence 

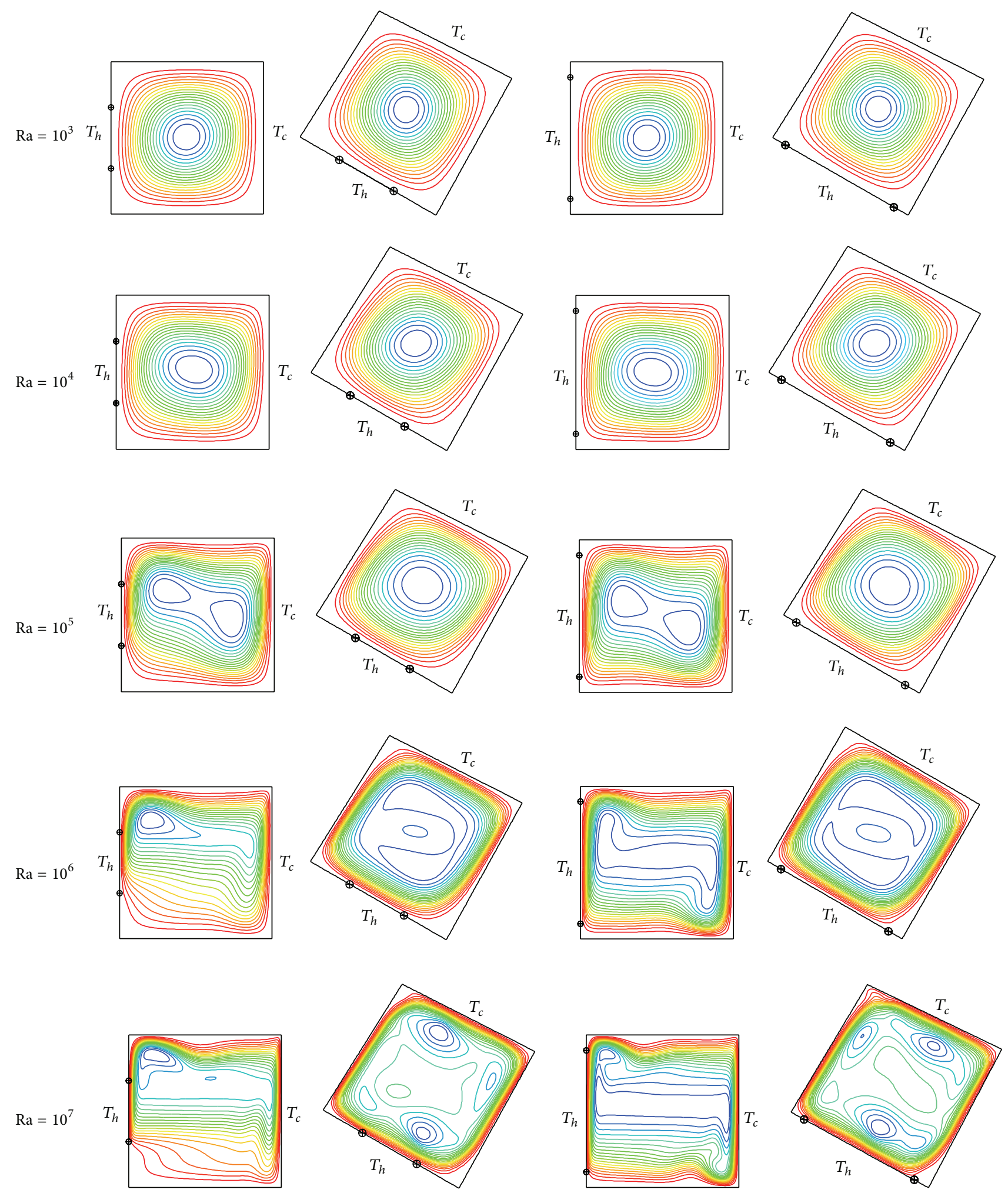

Figure 5: Streamlines for $A=0.4$ and 0.8 and $\theta=0^{\circ}$ and $60^{\circ}$. 

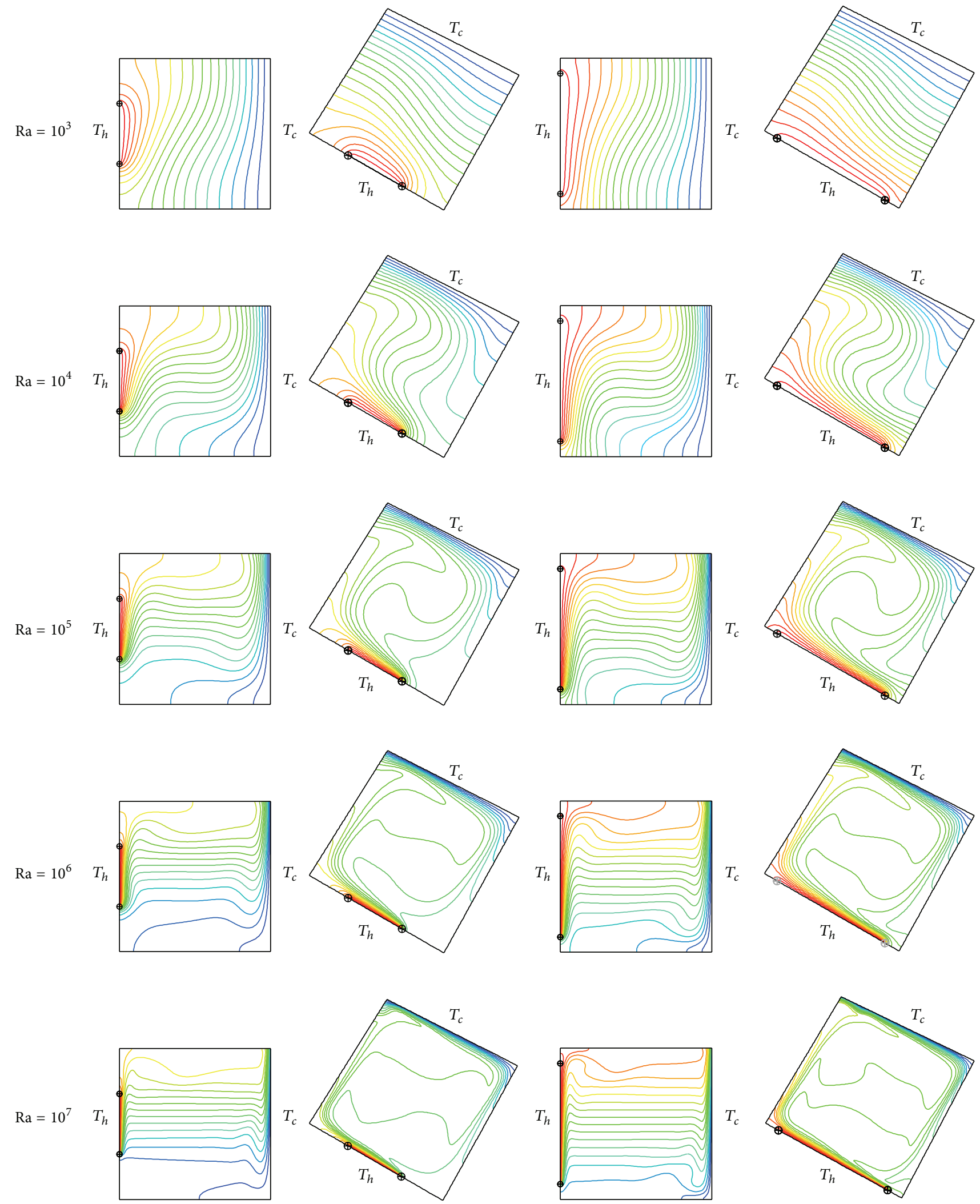

Figure 6: Isotherms for $A=0.4$ and 0.8 and $\theta=0^{\circ}$ and $60^{\circ}$. 


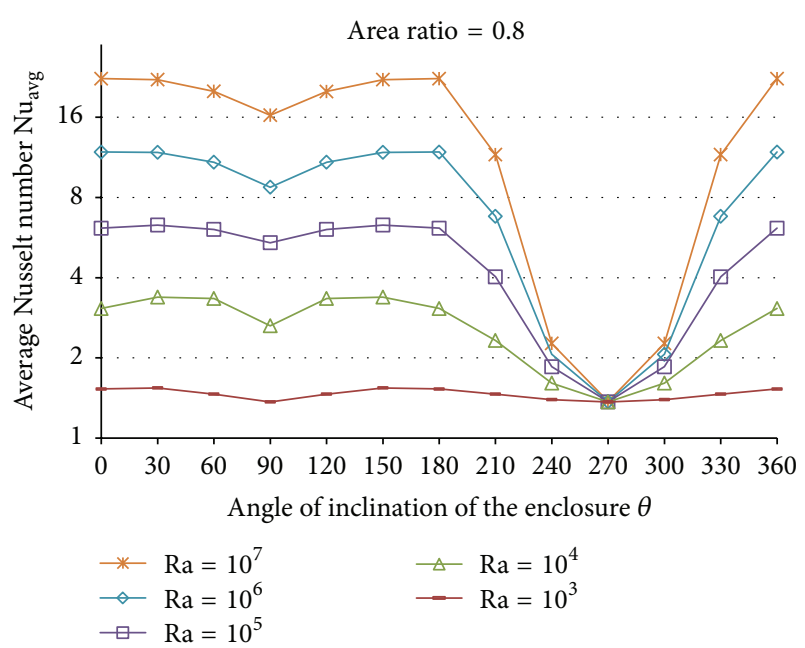

FIGURE 7: Variation of $\mathrm{Nu}_{\text {avg }}$ with $\theta$ at different Rayleigh numbers for $A=0.8$.

of these two parameters on temperature variation which in turn affects the rate of heat transfer. Thermal gradients are high near the hot and cold surfaces at all Rayleigh numbers. Isothermal lines are parallel to the hot and cold walls in the middle portion of the enclosure at low Rayleigh numbers and as the Rayleigh number increases these lines turn out to be almost perpendicular. The effect of angle of inclination of enclosure is noticeable in terms of isothermal lines plotted for $60^{\circ}$ angle of inclination. The isothermal lines are closely packed near the adiabatic wall which is on the downstream side of the heat source.

The effect of area ratio for the same Rayleigh number and the angle of inclination can also be observed in Figures 5 and 6 . Though the trends of the curves remain the same as the area ratio increases, additional concentration of the streamlines and isothermal lines is noticed, which indicates the increase in heat transfer rate with area ratio.

5.2. Variation of Average Nusselt Number. The angle of inclination of the enclosure $\theta$ strongly influences the natural convection heat transfer particularly at high Rayleigh numbers, due to change in streamline and isothermal line patterns. For illustration, the quantitative variations of average Nusselt number with $\theta$ for different Rayleigh numbers with hot surface area ratio equal to 0.8 are shown in Figure 7. At low Rayleigh numbers $10^{3}$ and $10^{4}$ the flow circulation within the enclosure is weak and hence average Nusselt number is independent of its angle of inclination. At high Rayleigh numbers the average Nusselt number decreases as $\theta$ increases from $0^{\circ}$ to $90^{\circ}$ and attains its initial value corresponding to $0^{\circ}$ when $\theta$ rises from $90^{\circ}$ to $180^{\circ}$. When $\theta$ is increased beyond $180^{\circ}$ and approaches $270^{\circ}$, the hot surface ascends above the centre of the enclosure and the cold surface moves towards the bottom level. The buoyancy force deviating away from the cold wall contributes additional drop in rate of heat transfer.
The lowest value of heat transfer rate is obtained at $\theta$ equal to $270^{\circ}$ in which the hot and cold surfaces are on the extreme upper and lower sides, respectively, and the direction of the buoyancy force is exactly towards the hot wall. Increasing $\theta$ from $270^{\circ}$ to $360^{\circ}$ changes the average Nusselt number to its initial value which corresponds to $0^{\circ}$ angle of inclination. The same trend of variation of $\mathrm{Nu}_{\text {avg }}$ with $\theta$ is observed for all the Rayleigh numbers investigated with different area ratios of the heat source.

5.3. Heat Transfer Dimensionless Correlations. In steady state condition all the heat flux $(q)$ from the heat source is absorbed by the cold wall and hence the $\mathrm{Nu}_{\mathrm{avg}}$ over the cold wall is a measure of heat transfer capacity of the enclosure. Based on the numerical results obtained in this study a correlation equation can establish the dependence of average Nusselt number on Rayleigh number and area ratio of the heat source, for a particular angle of inclination of the enclosure, as follows:

$$
\mathrm{Nu}_{\text {avg(corr) }}=\mathrm{CRa}^{m} A^{n} .
$$

The values of correlation coefficients $C, m$, and $n$ which are obtained by multiple regression analysis for all the investigated angles of inclination of the enclosure together with the maximum relative error $\eta$ and the average standard deviation $\sigma_{\text {avg }}(\%)$ are detailed in Table 1 . The values of $\eta$ and $\sigma_{\text {avg }}(\%)$ are estimated by the following equations as suggested by Chapra and Canale [23]:

$$
\begin{gathered}
\eta=\frac{\mathrm{Nu}_{\mathrm{avg}}-\mathrm{Nu}_{\mathrm{avg}(\text { corr })}}{\mathrm{Nu}_{\mathrm{avg}}} \\
\sigma_{\text {avg }}(\%)=\frac{100}{N} \sum_{1}^{N}\left|\frac{\mathrm{Nu}_{\mathrm{avg}}-\mathrm{Nu}_{\mathrm{avg}(\text { corr })}}{\mathrm{Nu}_{\mathrm{avg}}}\right| .
\end{gathered}
$$

The values of $\eta$ and $\sigma_{\text {avg }}$ (\%) vary between 0.0143 and 0.1523 and between 0.2216 and 3.567, respectively, which prove good agreement between the numerical results and the values obtained using correlation equation.

\section{Conclusions}

Natural convection heat transfer in a square enclosure heated from the discrete heat source and cooled from the opposite wall with the remaining walls insulated has been investigated. The studies are conducted for several area ratios of the heat source from 0.2 to 1.0 , for the angles of inclination of the enclosure $0^{\circ}$ to $360^{\circ}$, and for values of Rayleigh number in the range between $10^{3}$ and $10^{7}$. Streamline and isothermal line patterns are found to be similar for all the cases at low Rayleigh numbers whereas considerable differences are observed at high Rayleigh numbers. Studies conducted on the influence of angle of inclination reveal that the average Nusselt number decreases drastically as the position of the heat source is moved above the horizontal centre line of the enclosure. Heat transfer correlation equations have 
TABLE 1: Correlation coefficients with maximum relative error and average standard deviation in percentage.

\begin{tabular}{|c|c|c|c|c|c|c|}
\hline \multirow{2}{*}{$\theta$ (degrees) } & \multirow{2}{*}{$\mathrm{Ra}$} & \multicolumn{3}{|c|}{ Correlation coefficients } & \multirow{2}{*}{$\eta$} & \multirow{2}{*}{$\sigma_{\text {avg }}(\%)$} \\
\hline & & C & $m$ & $n$ & & \\
\hline \multirow{2}{*}{0} & $10^{3} \leq \mathrm{Ra}<10^{5}$ & 0.2394 & 0.2836 & 0.3271 & 0.1219 & 2.1823 \\
\hline & $10^{5} \leq \mathrm{Ra} \leq 10^{7}$ & 0.2954 & 0.2729 & 0.4744 & 0.0806 & 2.1533 \\
\hline \multirow{2}{*}{30} & $10^{3} \leq \mathrm{Ra}<10^{5}$ & 0.2375 & 0.2893 & 0.3211 & 0.1424 & 2.4248 \\
\hline & $10^{5} \leq \mathrm{Ra} \leq 10^{7}$ & 0.3360 & 0.2641 & 0.4536 & 0.0862 & 2.1493 \\
\hline \multirow{2}{*}{60} & $10^{3} \leq \mathrm{Ra}<10^{5}$ & 0.2217 & 0.2930 & 0.3049 & 0.1448 & 3.2234 \\
\hline & $10^{5} \leq \mathrm{Ra} \leq 10^{7}$ & 0.3837 & 0.2486 & 0.4235 & 0.0846 & 1.4617 \\
\hline \multirow{2}{*}{90} & $10^{3} \leq \mathrm{Ra}<10^{5}$ & 0.2332 & 0.2754 & 0.4722 & 0.1520 & 1.7173 \\
\hline & $10^{5} \leq \mathrm{Ra} \leq 10^{7}$ & 0.3126 & 0.2514 & 0.4203 & 0.1423 & 1.9605 \\
\hline \multirow{2}{*}{120} & $10^{3} \leq \mathrm{Ra}<10^{5}$ & 0.2153 & 0.2955 & 0.3006 & 0.1523 & 3.2803 \\
\hline & $10^{5} \leq \mathrm{Ra} \leq 10^{7}$ & 0.3854 & 0.2481 & 0.4216 & 0.0831 & 1.5131 \\
\hline \multirow{2}{*}{150} & $10^{3} \leq \mathrm{Ra}<10^{5}$ & 0.2540 & 0.2772 & 0.2828 & 0.1305 & 3.5670 \\
\hline & $10^{5} \leq \mathrm{Ra} \leq 10^{7}$ & 0.2757 & 0.2752 & 0.4172 & 0.1418 & 3.2547 \\
\hline \multirow{2}{*}{180} & $10^{3} \leq \mathrm{Ra}<10^{5}$ & 0.2393 & 0.2836 & 0.3269 & 0.1217 & 3.1304 \\
\hline & $10^{5} \leq \mathrm{Ra} \leq 10^{7}$ & 0.2968 & 0.2729 & 0.4661 & 0.0856 & 1.2832 \\
\hline \multirow{2}{*}{210} & $10^{3} \leq \mathrm{Ra}<10^{5}$ & 0.4033 & 0.1996 & 0.3168 & 0.1001 & 2.9825 \\
\hline & $10^{5} \leq \mathrm{Ra} \leq 10^{7}$ & 0.4287 & 0.2075 & 0.5371 & 0.1072 & 2.1582 \\
\hline \multirow{2}{*}{240} & $10^{3} \leq \mathrm{Ra}<10^{5}$ & 1.0060 & 0.0557 & 0.2409 & 0.0418 & 1.6211 \\
\hline & $10^{5} \leq \mathrm{Ra} \leq 10^{7}$ & 1.1381 & 0.0464 & 0.2659 & 0.0143 & 0.2221 \\
\hline \multirow{2}{*}{270} & $10^{3} \leq \mathrm{Ra}<10^{5}$ & 1.3883 & 0.0025 & 0.2005 & 0.0215 & 1.1462 \\
\hline & $10^{5} \leq \mathrm{Ra} \leq 10^{7}$ & 1.2618 & 0.0082 & 0.1530 & 0.0351 & 0.3612 \\
\hline \multirow{2}{*}{300} & $10^{3} \leq \mathrm{Ra}<10^{5}$ & 1.0078 & 0.0555 & 0.2416 & 0.0423 & 1.6220 \\
\hline & $10^{5} \leq \mathrm{Ra} \leq 10^{7}$ & 1.1381 & 0.0464 & 0.2659 & 0.0143 & 0.2216 \\
\hline \multirow{2}{*}{330} & $10^{3} \leq \mathrm{Ra}<10^{5}$ & 0.4033 & 0.1996 & 0.3169 & 0.0999 & 2.9814 \\
\hline & $10^{5} \leq \mathrm{Ra} \leq 10^{7}$ & 0.2878 & 0.2397 & 0.6835 & 0.0768 & 1.0799 \\
\hline \multirow{2}{*}{360} & $10^{3} \leq \mathrm{Ra}<10^{5}$ & 0.2394 & 0.2836 & 0.3271 & 0.1219 & 2.1823 \\
\hline & $10^{5} \leq \mathrm{Ra} \leq 10^{7}$ & 0.2954 & 0.2729 & 0.4744 & 0.0806 & 2.1533 \\
\hline
\end{tabular}

been developed for each angle of inclination of enclosure investigated which are in good agreement with the numerical results.

\section{Nomenclature}

A: $\quad$ Area ratio of heat source $(S \times 1 / L \times 1)$

g: Acceleration due to gravity

L: $\quad$ Length of the enclosure wall

$\mathrm{Nu}$ : Nusselt number

$\mathrm{Nu}_{\text {avg }}$ : Average Nusselt number

$p$ : $\quad$ Fluid static pressure

Pr: Prandtl number

q: $\quad$ Heat flux

Ra: Rayleigh number

S: $\quad$ Length of the heat source

T: $\quad$ Temperature

$T_{c}$ : $\quad$ Temperature of cold wall

$T_{h}$ : Temperature of the heat source

$u, v: \quad$ Velocity components in $x$ and $y$ directions

$x, y: \quad$ Cartesian coordinates

$C, m, n$ : Correlation coefficients.
Greek Symbols

$\alpha$ : Thermal diffusivity

$\beta$ : Volume expansion coefficient

$\theta$ : Angle of inclination of the enclosure

$v$ : Kinematic viscosity

$\rho: \quad$ Fluid density

$\eta$ : $\quad$ Maximum relative error

$\sigma_{\text {avg }}$ : Average standard deviation.

Subscripts

c: $\quad$ Cold wall

$h$ : Hot wall

avg: Average value

corr: Correlation.

\section{Conflict of Interests}

The authors declare that there is no conflict of interests regarding the publication of this paper. 


\section{References}

[1] D. C. Wan, B. S. V. Patnaik, and G. W. Wei, "A new benchmark quality solution for the buoyancy-driven cavity by discrete singular convolution," Numerical Heat Transfer, Part B: Fundamentals, vol. 40, no. 3, pp. 199-228, 2001.

[2] N. C. Markatos and K. A. Pericleous, "Laminar and turbulent natural convection in an enclosed cavity," International Journal of Heat and Mass Transfer, vol. 27, no. 5, pp. 755-772, 1984.

[3] P. Le Quere, "Accurate solutions to the square thermally driven cavity at high Rayleigh number," Computers and Fluids, vol. 20, no. 1, pp. 29-41, 1991.

[4] G. Barakos, E. Mitsoulis, and D. Assimacopoulos, "Natural convection flow in a square cavity revisited: laminar and turbulent models with wall functions," International Journal for Numerical Methods in Fluids, vol. 18, no. 7, pp. 695-719, 1994.

[5] Y. Mao and Y. Zhang, "Evaluation of turbulent models for natural convection of compressible air in a tall cavity," Numerical Heat Transfer, Part B: Fundamentals, vol. 64, no. 5, pp. 351-364, 2013.

[6] J. Patterson and J. Imberger, "Unsteady natural convection in a rectangular cavity," Journal of Fluid Mechanics, vol. 100, no. 1, pp. 65-86, 1980 .

[7] P. Kandaswamy, S. Sivasankaran, M. Bhavanilakshmi, and R. S. Ramaswamy, "Convection in a cavity with variable viscosity fluid," Indian Journal of Pure and Applied Mathematics, vol. 36, no. 1, pp. 641-650, 2005.

[8] M. V. Joshi, U. N. Gaitonde, and S. K. Mitra, "Analytical study of natural convection in a cavity with volumetric heat generation," Journal of Heat Transfer, vol. 128, no. 2, pp. 176-182, 2006.

[9] C. An, C. B. Vieira, and J. Su, "Integral transform solution of natural convection in a square cavity with volumetric heat generation," Brazilian Journal of Chemical Engineering, vol. 30, no. 4, pp. 883-896, 2013.

[10] G. Saha, S. Saha, and A. H. Mamun, "A finite element method for steady state natural convection in a square tilt open cavity," ARPN Journal of Engineering and Applied Sciences, vol. 2, no. 2, pp. 41-49, 2007.

[11] M. Corcione, "Effects of the thermal boundary conditions at the sidewalls upon natural convection in rectangular enclosures heated from below and cooled from above," International Journal of Thermal Sciences, vol. 42, no. 2, pp. 199-208, 2003.

[12] M. Samy and Elsherbiny, "Laminar natural convection in shallow air rectangular cavities," Alexandria Engineering Journal, vol. 43, no. 5, pp. 603-613, 2004.

[13] S. M. Aminossadati and B. Ghasemi, "The effects of orientation of an inclined enclosure on laminar natural convection," International Journal of Heat and Technology, vol. 23, no. 2, pp. 43-49, 2005.

[14] P. Kandaswamy and M. Eswaramurthi, "Density maximum effect on buoyancy-driven convection of water in a porous cavity with variable side wall temperatures," International Journal of Heat and Mass Transfer, vol. 51, no. 7-8, pp. 1955-1961, 2008.

[15] M. Eswaramurthi and P. Kandaswamy, "Transient doublediffusive convection of water around $4^{\circ} \mathrm{C}$ in a porous cavity," Journal of Heat Transfer, vol. 131, no. 5, Article ID 052601, 7 pages, 2009.

[16] A. Himsar, K. Kouki, D. Mashasi, S. Takeo, T. Hiroshi, and S. Jun, "Laminar natural convection heat transfer in an air filled square cavity with two insulated baffles attached to its horizontal walls," Thermal Science and Engineering, vol. 14, no. 3, pp. 35-46, 2006.
[17] K. Kahveci, "Natural convection in a partitioned vertical enclosure heated with a uniform heat flux," Journal of Heat Transfer, vol. 129, no. 6, pp. 717-726, 2007.

[18] X. Shi and J. M. Khodadadi, "Laminar natural convection heat transfer in a differentially heated square cavity due to a thin fin on the hot wall," Journal of Heat Transfer, vol. 125, no. 4, pp. 624634, 2003.

[19] J. F. Zou, Y. Gao, and W. K. Chow, "Numerical simulations on laminar natural convection in a square cavity with a conducting circular block," International Journal of Heat and Technology, vol. 28, no. 1, pp. 1-8, 2010.

[20] Aswatha, C. J. Gangadhara Gowda, S. N. Sridhara, and K. N. Seetharamu, "Effect of different thermal boundary conditions at bottom wall on natural convection in cavities," Journal of Engineering Science and Technology, vol. 6, no. 1, pp. 109-130, 2011.

[21] D. D. Gray and A. Giorgini, "The validity of the boussinesq approximation for liquids and gases," International Journal of Heat and Mass Transfer, vol. 19, no. 5, pp. 545-551, 1976.

[22] S. V. Patankar, Numerical Heat Transfer and Fluid Flow, Hemisphere Publications, Washington, DC, USA, 1980.

[23] S. C. Chapra and R. P. Canale, Numerical Methods for Engineers, McGraw-Hill, Singapore, 3rd edition, 2008. 


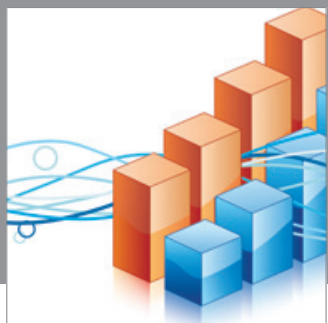

Advances in

Operations Research

mansans

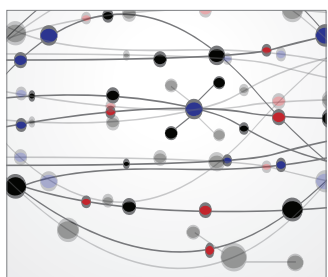

The Scientific World Journal
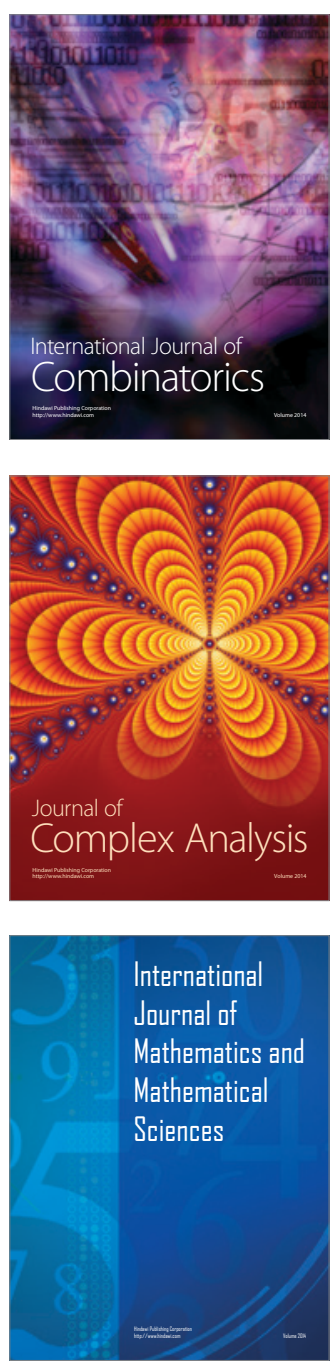
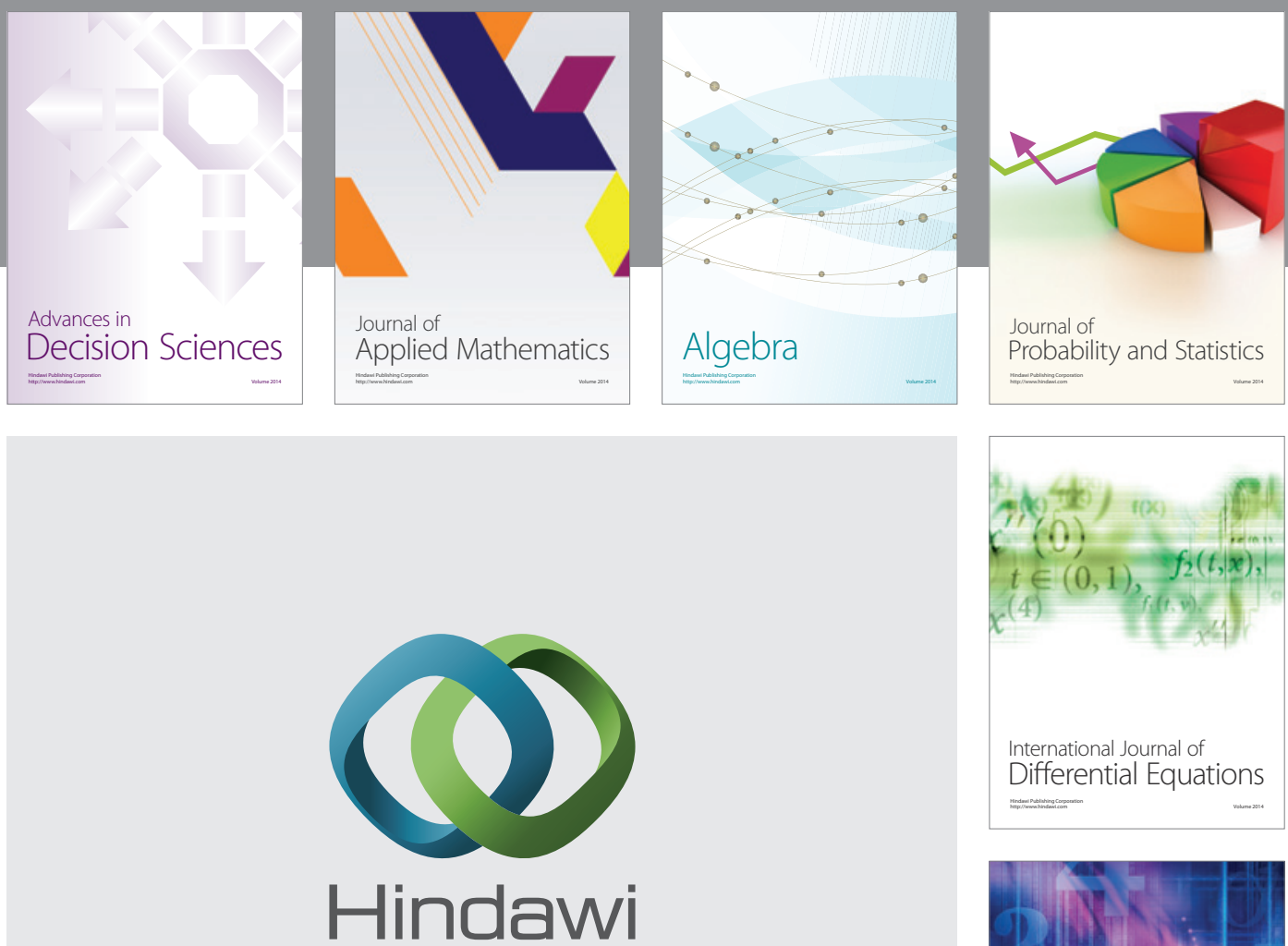

Submit your manuscripts at http://www.hindawi.com
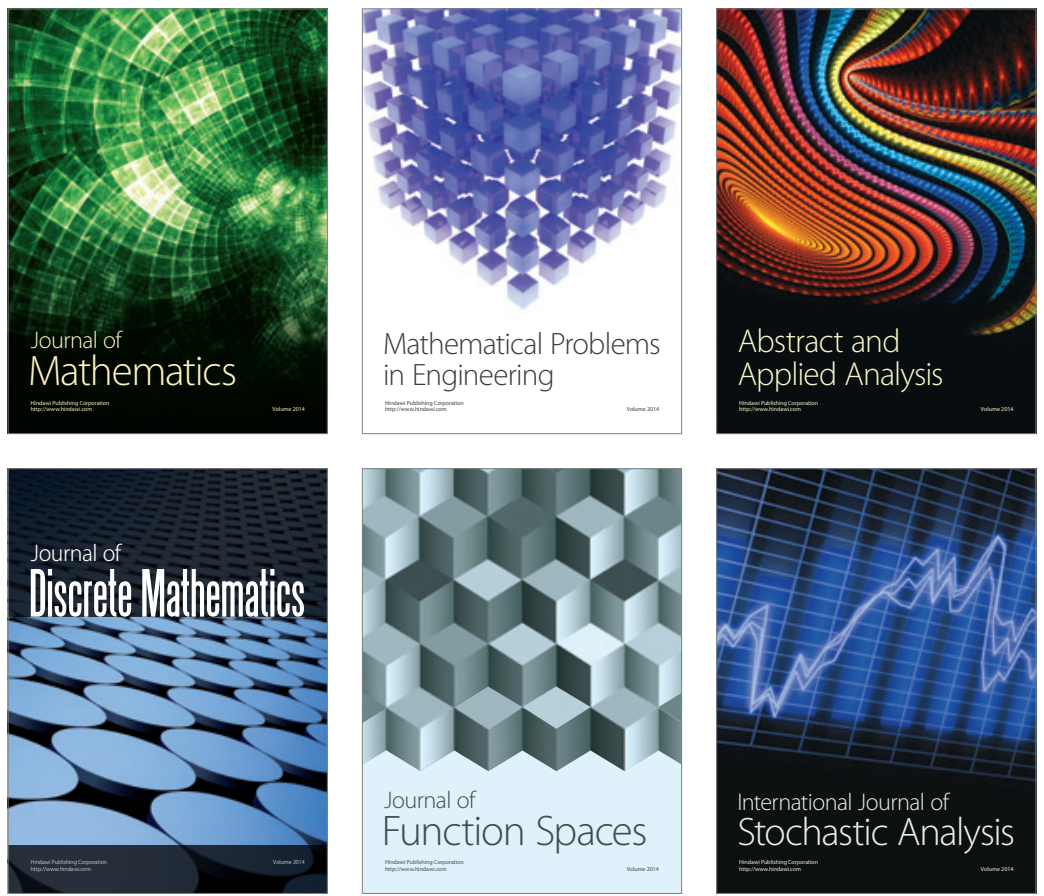

Journal of

Function Spaces

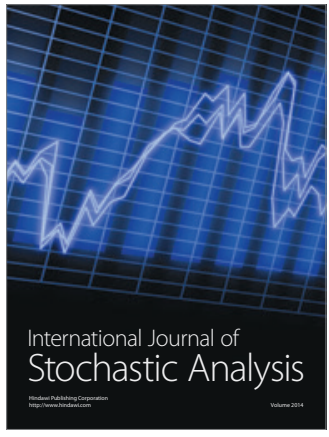

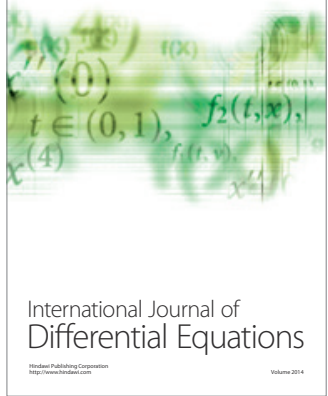
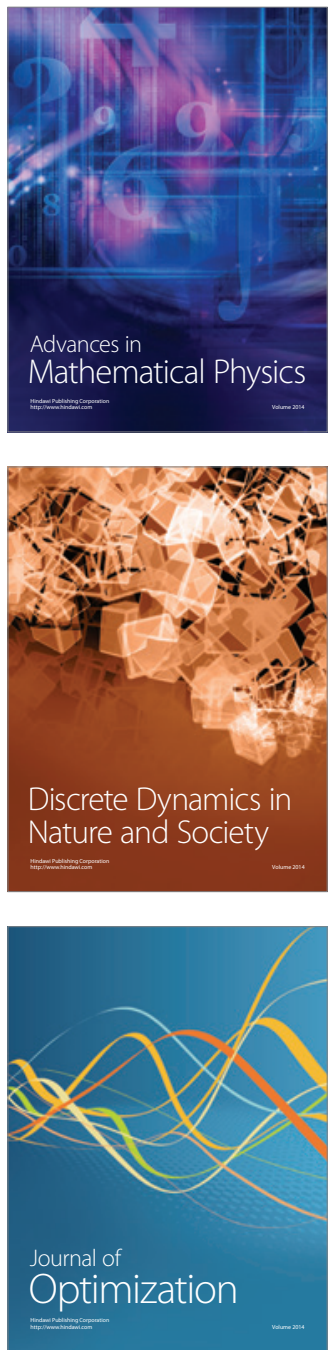